\title{
Challenges in Developing 'Insight Learning' in the Virtual Learning Environment with Special Reference to Gestalt Theory of Perception
}

\section{Somasundaram Jeganathan}

\author{
Ph.D. Research Scholar, \\ Department of Philosophy, Annamalai University, India; \\ Senior Lecturer, Dept. of Philosophy and Value Studies, \\ Eastern University, Sri Lanka
}

\section{Thanigaivelan Shanmugam}

\author{
Assistant Professor, Department of Philosophy, \\ Annamalai University, Annamalai Nagar, \\ Chidambaram, 6o8oo2, Tamil Nadu, India
}

DOI: https://doi.org/10.36941/jesr-2022-0oo8

\begin{abstract}
A paradigm shift has altered our world in practically every sphere and it can be attributed to the Covid-19 pandemic. Modern science and technologies have been called upon to redesign various processes in order to cope with this outbreak and the changes it has wrought. Even the world of education has been subject to severe disruption. To deal with the new situation, the students and teachers have been forced to change the way they customarily taught, learnt and interacted. The entire educational framework will have to be transformed from the traditional face-to-face or physical system to the virtual Moodle education system. The entire school system and higher education system in Sri Lanka are now called upon to confront these new challenges if they are to continue the learning and teaching processes. Fortunately, the higher education institutions have managed to find a quick remedy, by moving to online learning to overcome the difficult situation. Although many learning theories have been introduced to evaluate the learning processes in the physical classroom, the Gestalt learning theory is slightly different from the other theories. This is because the Gestalt theorists emphasize the need for whole perception, which can only be achieved by focusing on the entire learning process and making sense of things by thinking of them deeply. The process of thinking involved selecting, organizing, interpreting and creating meaning. This processing method is called 'insight learning'. Hence, this study is an attempt to assess the feasibility of developing insight learning in virtual learning. The data was collected through Google forms, and the conclusion is based on the more than 700 responses received from undergraduate students in the Faculty of Arts and Culture, Eastern University, Sri Lanka. The SPSS software was used to record and analyze data using factor analysis and descriptive statistics. The study shows that there are many factors that prove to be obstacles in the way of developing insight learning via an online learning system. Therefore, the study recommends some strategies to overcome these obstacles and adopt the new online learning process in the future.
\end{abstract}

Keywords: Covid-19, Gestalt theory, Insight, Perception, Virtual Learning 


\section{Introduction}

The Covid-19 pandemic has been disrupting the normal functioning of many sectors in Sri Lanka ever since its outbreak in January 2020. The Sri Lankan government was forced to impose a nationwide curfew from $20^{\text {th }}$ March 2020 to $24^{\text {th }}$ March 2020. Aiming to control the pandemic, the government enforced a strict program of case detection, identification of contacts, quarantining, travel restrictions, and isolation of Covid hotspots as well. By adjusting the strategy in a timely manner, the authorities were successful in limiting the infected persons to 2,810 cases as of $29^{\text {th }}$ July 2020 . No community cases were reported in the country after $30^{\text {th }}$ April 2020 (Erandi et al., 2020: 01).

The World Health Organization (WHO) declared Covid-19 as a pandemic on $11^{\text {th }}$ March 2020 (Kumari \& Jayasinghe, 2021). Following that, the government ordered all educational institutions to close from 12 March 2020. This included all schools and higher educational institutions, comprising 15 state universities and about 40 other state and non-state tertiary educational institutions. Prolonged disruptions to tertiary education could delay the entry of graduates and skilled workers into the labor market, depriving the country of a capable workforce that it needs to transition to the upper-middle-income status (Hayashi, Garcia, et al., 2020: 02).

In this situation, Sri Lanka's higher education institutions faced difficult conditions in conducting classes for the students. The continuous lockdown has had a significant impact not only on students' education but also students' mental health (Rameez et al., 2020: 342). Moreover, this led to about half a million undergraduate and graduate students to halt their studies indefinitely. In the meantime, the University Grants Commission (UGC) has taken several measures to provide "nonstop education" to students through online learning systems (Weerathunga, Samarathunga, et al., 2021: 02). As for the online learning system, the UGC and Telecommunications Regulatory Commission of Sri Lanka (TRCSL) reached an agreement with all Internet service providers in Sri Lanka to provide free online access to students so that they could continue their studies through university Learning Management Systems (LMS) and remote learning facilities set up by the Lanka Education and Research Network (LEARN) (Hayashi, Garcia, et al., 2020: 02).

The University Grants Commission (UGC) has already arranged to continue part of the learning and teaching process via the online system. However, conducting all of the learning activities through the online system has presented many challenges to both teachers and students. The reason is that, earlier the majority of degree programs were conducted under traditional face-to-face lecture hall methods for Sri Lankan undergraduates (Kumari \& Jayasinghe, 2021). Before the higher educational institutions introduced their online learning system, they considered many things to make this process effective. Availability of network systems around the country, students' level of accessibility to virtual learning facilities, adequate knowledge to interact with the technological platforms, adequate financial support during the pandemic to pay the service providers, students' confidence in and satisfaction with the virtual learning environment, and belief in blended learning method, etc. are necessary for the construction of a strong platform for learning.

Indeed, academic institutions will not be able to transform their course curricula into online resources overnight (Dhawan, 2020: 08). In the meantime, there are fewer opportunities to apply the learning theories used in the physical classroom to the virtual learning environment. Terry Anderson (2011: 47) emphasizes that this online learning process is learning-centered instead of learnercentered. Most of the earlier learning theories were established under the label of learner-centered. Hence, there is a challenge to be faced when applying traditional learning theories to an online learning system.

A solution for these issues may be Gestalt learning theory, which promotes insight learning. The insight learning processes guide the learner to perceive the situation and understand the relationships between various factors. Finally, he/she makes the proper decision intelligently (Manoharan, 2009: 198). Thus, cognitive processes are essential for insight learning. Cognitive theorists promoted the concept that the mind has a vital role to play in learning by focusing on what happens between an environmental stimulus and student response (Picciano, 2017: 167). According to 
Roddy, Lalaine et al. (2017), there are many challenges involved in applying online learning and teaching and also supporting the intensive online environment.

Sri Lankan education system that is based on the traditional methods has been practiced for a long time. Therefore, before shifting from that traditional system to an E-learning system, it is necessary to research the effectiveness and success of E-learning and the issues facing students who learn through this process. That will be helpful for the government, universities, and other educational institutes to make decisions, formulate policies, organize learning, and introduce new degree programs based on the results of researches. Presently, there is a paucity of research on this issue both in Sri Lanka and the world (Haththotuwa \& Rupasinghe, 2021: 149).

To fill in these gaps, this study aims to identify the conceptual frameworks pertaining to insight learning and virtual learning and their relationship. Then this study will focus on the challenges while implementing those learning systems during the pandemic. Further, this study recommends strategies and approaches for establishing a solid platform for online learning in the future. However, this study makes a significant contribution toward the feasibility of using online learning for higher education according to the learning theories, especially Gestalt learning theory. We could not find any published work or survey conducted inside the country on this topic. It was the crucial need for filling this research gap that motivated us to conduct this research.

\section{Literature Review}

We conducted an extensive literature review so that we could better elaborate on both virtual learning and insight learning. Virtual learning is defined as learning that can functionally and effectively occur in the absence of a traditional classroom environment (Simonson \& Schlosser, 2006). In other words, Virtual learning refers to digital/ computer-based learning environments (Weiss, Nolan et al., 2006: 03) while it is also understood to cover the existing online learning environment, including electronic learning, mobile learning, and ubiquitous learning (Temdee, 2020).

The history of the development of network communications began in the late 196os with the advent of e-mail and computer conferencing in 1971. In the 1980 s and 1990 innovation and expansion in e-learning and networking proceeded apace in public schooling and even adult education. These developments laid a solid foundation that enabled virtual learning to gain acceptance all over the world (Weiss, Nolan et al., 2006: 57). Thus, in the early 21st century, this shift became civilizational and assumed a global character as educators and learners worldwide adopted the network based elearning method.

There are both advantages as well as disadvantages to virtual learning. The advantages are better time management, association with technology, reduced costs, acquisition of transferable skills, and availability of lecture notes to everyone concerned, etc. In contrast, the disadvantages are the lack of eye contact, network issues, passive learning situation, and the impracticality of performing laboratory activities online. Also, both students and teachers need technical training and support to work in a virtual environment (Cvetkovic, 2016: 03).

Many developed countries have implemented and been conducting online learning programs to facilitate distance learning for students. However, the developing countries are primarily continuing with the traditional method of teaching. The rapid paradigm shift that has occurred in the learning process due to the outbreak of Covid-19 has confronted the developing countries with the necessity of switching over to the online learning process. The trouble is that both public and private educational institutions have faced issues in such areas as developing online lessons, overcoming technical problems, finding free online resources relevant to courses, and setting up new learning spaces for autonomous learning. All these processes are essential to achieve success in online education for tertiary level students (Hu \& Driscoll, 2013).

Even though numerous issues have surfaced in this online learning and teaching process, most countries were forced to switch over to this method at short notice in order to continue non-stop learning activities. Hence, much research will have to be done to establish a strong foundation for 
virtual learning in future. Because the online learning system has transformed from an optional method to a necessary method, there is a need for educationists to work hard to create a good learning environment for students by introducing suitable learning theories, tools, and approaches. As such, good management is imperative to make this learning system useful to the students.

The question "How do we learn?" has occupied the minds of philosophers, thinkers and researchers at least from the time of Socrates, Plato, Aristotle and Pythagoras. Allied with this is the question of, "How do we then teach to ensure learning occurs?" The mystery surrounding the acquisition of knowledge and the best pedagogical practices to maximize effective learning has resulted in many differing theories, especially in modern times with the rise of educational psychology (Ovens, 2017). Among those learning theories, Gestalt learning theory is one of the most influential.

Gestalt theory began in the late $19^{\text {th }}$ century in Germany and Austria. It is based upon the idea that the experience of the human being is a unified whole. Gestalt psychology argues that human beings perceive things in terms of their entire configuration or complete structure and not as made up of individual tiny parts. It assumes that the whole is more than the sum of its parts. It is correct to say that the whole is different from its parts because simple summing is meaningless, whereas the whole-part relationship is meaningful (Koffka, 1936: 176).

The concept of 'Gestalt theory' is an alternation between behaviorism and structuralism. Before the arrival of Gestalt theory, the earlier schools of psychology used molecular approaches that sought to reduce conscious experience to fundamental elements. Gestalt argued that reduction is destruction. Only a molar or phenomenological approach can perceive the conscious experience as it is really lived out.

The prominent figures of Gestalt theory were Max Wertheimer, Kurt Koffka and Wolfgang Kohler. They claimed this learning theory is superior to the Stimulus-Response approach to learning. To understand this better, Kohler conducted several experiments on a monkey named Sultan, and finally he concluded that the best way of learning is through insight.

The three main experiments of Kohler with the chimpanzee, Sultan, illustrate the idea of insight. Kohler put the hungry Sultan inside a big cage and hung a bunch of bananas from the roof. Sultan kept jumping up to get at the bananas but did not succeed. Kohler had also kept a box inside the cage. The chimpanzee later stopped jumping and placed the box under the bunch, climbed on it and reached the bananas easily. The following experiment was made more difficult by tying the bananas much higher but two boxes were kept in the cage. Now, Kohler observed that the chimpanzee placed one box over the other and reached the banana. The final experiment was more complex than the previous ones. This time, Sultan was inside the cage, but the bananas were placed outside the cage, beyond the reach of the animal's hands. Two sticks, one longer and the other shorter were placed in the cage. Each stick by itself was too short to grasp the bananas. After several failed attempts, Sultan managed to join both sticks together and was able to pull the bananas towards the cage (Manoharan, 2009: 197-198).

Kohler concluded that apes did not carry out these missions through trial and error or luck, but used 'introspection'. He explained the apes' problem-solving behavior in terms of cognitive processes (Celikoz et al., 2019: 25). Kohler stated in his famous work, The Mentality of Apes (1925) that Sultan after trying out various stratagems, "put the stick in the hole," and joined the two bamboo rods together. This is precisely the same as if he had discovered the new procedure as a genuine solution. After this, there is no doubt that he used the double stick technique whenever the need arose. His various attempts to solve the problem may have eventually led him to this "insight" (Kohler, 1925: 202).

His extensive research findings on learning were published by Koffka in his work, Principles of Gestalt Psychology (1935). He pointed out that the law of perception can be applied to learning. After investigating earlier learning processes, he suggests that this perception is a new process (Koffka, 1935: 548). The learning situation is based on the problem situation, and the learning motivation is to find out the solution to the problem. Therefore, the learner should consider the problem as a whole 
and find its solution through insight.

The key factors influencing insight learning are past experiences, level of intelligence, learning situation, initial efforts, repetition, and generalization. Moreover, when a learner observes the problem as a whole, he can find a solution inside. So, Koffka proposed that the law of perception was appropriate to learning. Those laws are the law of similarity, the law of closure, the law of proximity, and the law of good continuation.

Therefore, the Gestalt psychologists proposed a learning theory that was markedly in contrast to the behaviorists' view. Additionally, Gestalt emphasized that more than through observable behavior, learning can take place by insight. So, in order to develop the insight, we need to make a strong observation of the problem. Thus, various factors such as learning environment, teacher - student relationship, mutual understanding, motivation, feelings and emotions, beliefs and confidence, and numerous other things influence insight learning.

\section{Research Problem}

The Covid-19 pandemic has caused disruptions on a global scale in almost every sector. Even though many countries have reined in their various activities, many of them have attempted to continue their educational activities without a break. In Sri Lanka, the Ministry of Education and Higher Education has also made every endeavor to carry on the educational activities by one means or the other. Fortunately, due to the development of Information and Communication Technology, the concerned authorities were able to achieve a degree of success in this matter. In these circumstances, this research focuses on "How far-reaching is the effectiveness of virtual learning in developing students' knowledge, skills, and attitudes" as the problem of this study.

\section{Methodology}

In this Covid-19 pandemic period, the feasibility of using virtual learning in higher education according to the learning theories has become a hot topic. However, we could not find any published work or survey conducted inside the country on this topic. The important need to fill this knowledge gap motivated us to conduct this research.

The first-year undergraduate students of the academic year 2018/2019 at the Faculty of Arts and Culture, Eastern University, Sri Lanka, were selected as the sample of this study. The survey covered all of the first-year students at this faculty and the conclusion is based on the 484 responses received from them.

An online questionnaire was prepared and developed using Google forms and shared online for data collection. This questionnaire included questions on seven (o7) factors, and the number of questions was limited to 33. The questions were designed to cover all the objectives of the study.

The data were collected ensuring there was no bias by adopting a statistical approach like simple random sampling. Then the Statistical Package for the Social Sciences (SPSS) was used to analyze the data. Further findings and recommendations were based on the results of the data analysis.

\section{Results and Discussion}

Thus, data were collected from 484 first-year students of the Faculty of Arts and Culture, to investigate the feasibility of developing insight learning through the online or virtual education system. Some subcategories were also identified to explain the findings, such as respondent information and background, models and learning platforms used during the pandemic, challenges facing online learning, satisfaction and confidence in online learning, and suggestions for future online education. 


\subsection{Respondent Information}

According to the respondent information, $82.6 \%$ were female students, while $17.4 \%$ were male students. All these students contributed their ideas based on the research questions. Even the focus group was comprised of first-year undergraduates, and it was found that $4.4 \%$ of the students were married. $2.9 \%$ of students were having a part-time job while $4.8 \%$ were self-employed. However, most of the students were unemployed and depended on their parents to support them. It is worth noting that the families of $32.5 \%$ of students in the sample had an income of less than Rupees 10,000 per month. In fact, the highest percentage of families fell into this income bracket. Only a small percentage of students (7.3\%) had more than Rupees 40,000 as their family income. It also came to light that $6.3 \%$ of students had no family income to speak of. Overall there is a neutral stage of satisfaction on their family income.

\subsection{Models E Learning Platforms Used during the Covid-19 Pandemic}

During the pandemic, the students and teachers have been continuing their learning and teaching activities through online learning systems worldwide. Developed countries have carried out their virtual learning activities successfully while developing countries have been facing lots of challenges. In this context, university students in Sri Lanka also have been advised to continue their learning through the online system.

However, the government and the educational authorities seem to be of the opinion that the level of knowledge of students and teachers in information and communication technology (ICT) is not sufficient to engage in online education. According to our respondents, they have only a marginal level of knowledge of ICT and little experience in handling the online learning system. Most of the students feel the need to get training in ICT and this is true for the teachers too. Training for both students and teachers is vital to ensure more effective online learning in the future.

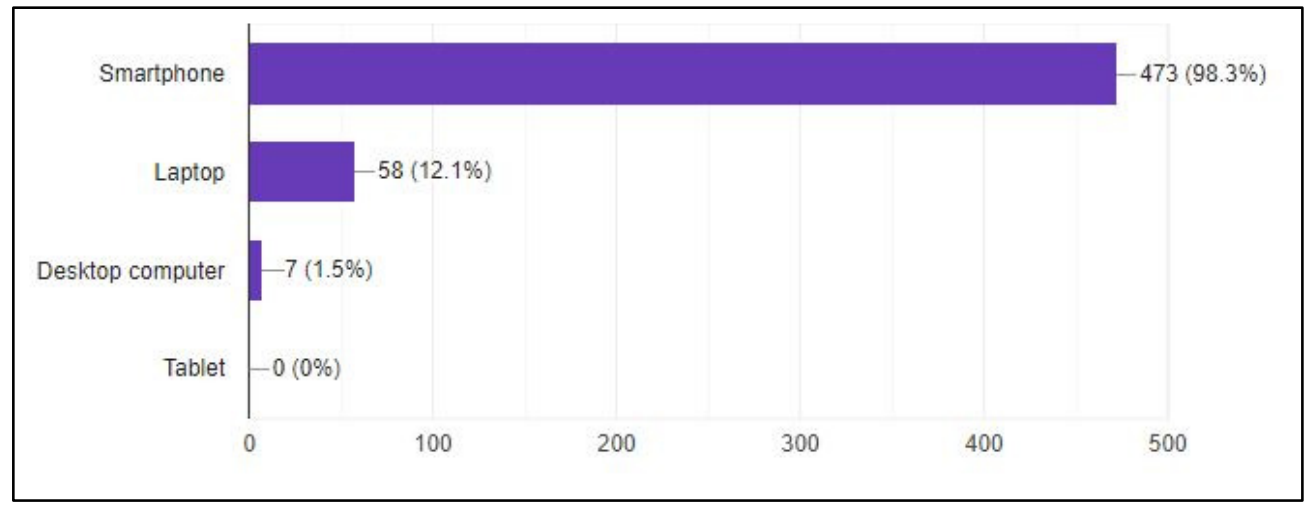

Figure 1: Devices used for online learning

Among the responding first-year students, 98.3\% have used smartphones, and $12.1 \%$ have used laptops for online learning. Figure 1 describes the popularity of usage of the different devices. A few students have used desktop and laptop computers for online learning but most have used smartphones. We allowed them to select more than one option since many students use more than one type of device for online learning during this Covid-19 period. 


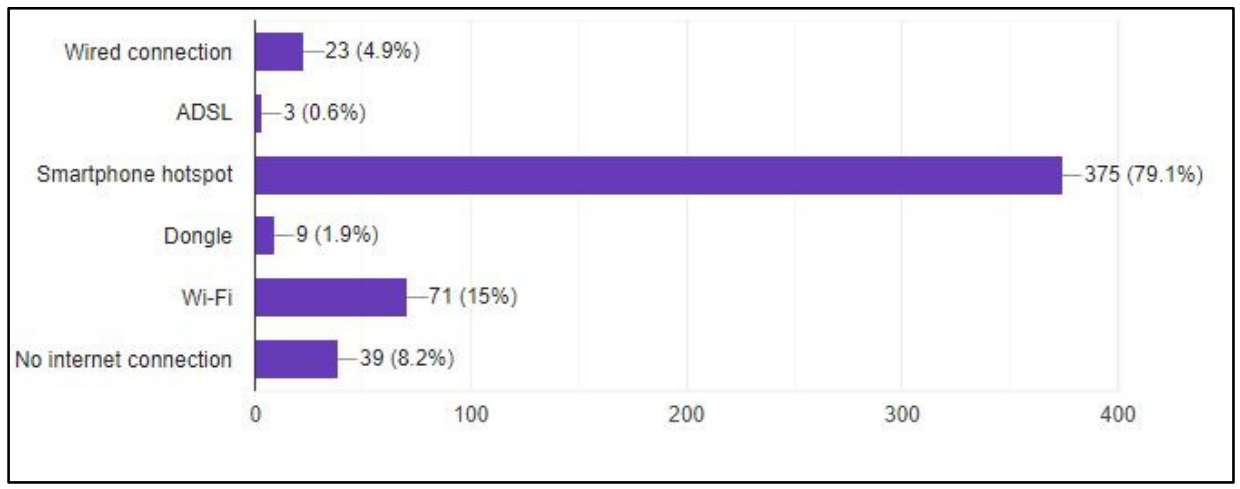

Figure 2: Mode of Connecting to the Internet

Then we checked the mode of connecting to the Internet, and for this too, the students depended on different ways of accessing the Internet. As shown in Figure 2, most of them connected to the Internet through the $3 \mathrm{G}$ or $4 \mathrm{G}$ feature built into their smartphones $(79.1 \%)$, while a few students used Wi-Fi routers $(15 \%)$. A small number used $3 \mathrm{G}$ or $4 \mathrm{G}$ dongles $(1.9 \%)$. Some respondents stated they were using wired connections with a basic modem (4.9\%) or ADSL modem (o.6\%), to connect to the Internet. Therefore, it turned out that most students were connected to the Internet by the $3 \mathrm{G}$ or $4 \mathrm{G}$ signal picked up by their smart phones.

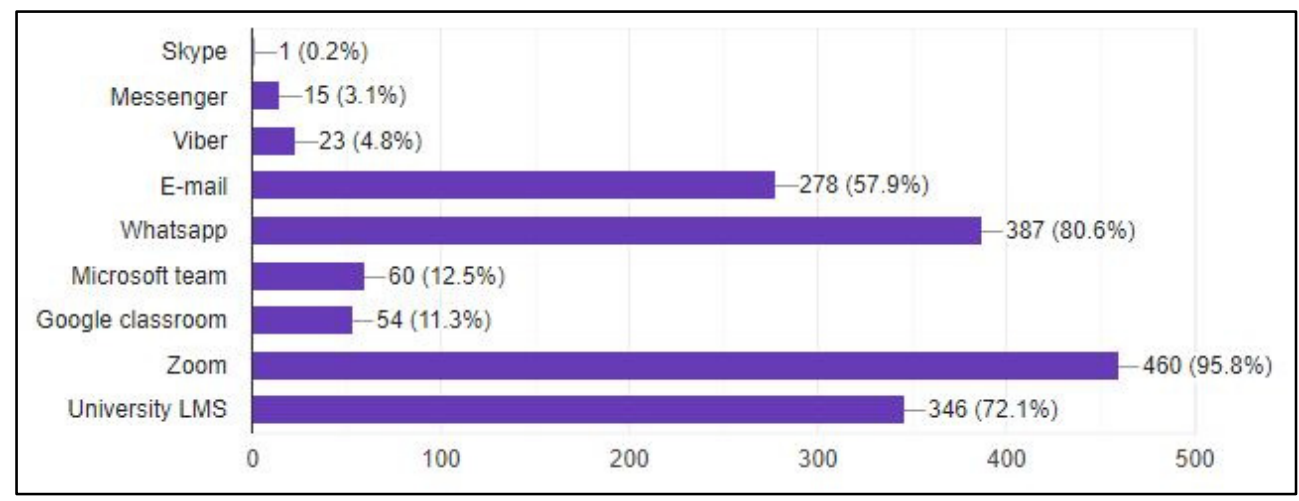

Figure 3: Learning Platforms used during the Covid-19 pandemic

According to Figure 3, students have tried out and often use more than one learning platform for their online learning activity. We can see that even social media platforms have been used for the study purpose. During this pandemic, most of the students are engaged in online learning via Zoom (95.8\%). A considerable number of students also use university LMS (72.1\%). According to the responses of students, WhatsApp plays a vital role in their online learning by facilitating the sharing of materials and allowing peer group interactions, which are all done by creating WhatsApp groups. The survey also found that E-mail (57.9\%), Microsoft Team (12.5\%), and Google Classroom (11.3\%) have been used for online learning to a fair extent. Meanwhile, Skype, Messenger, and Viber have played only a small part in online learning, each accounting for less than $5 \%$. 


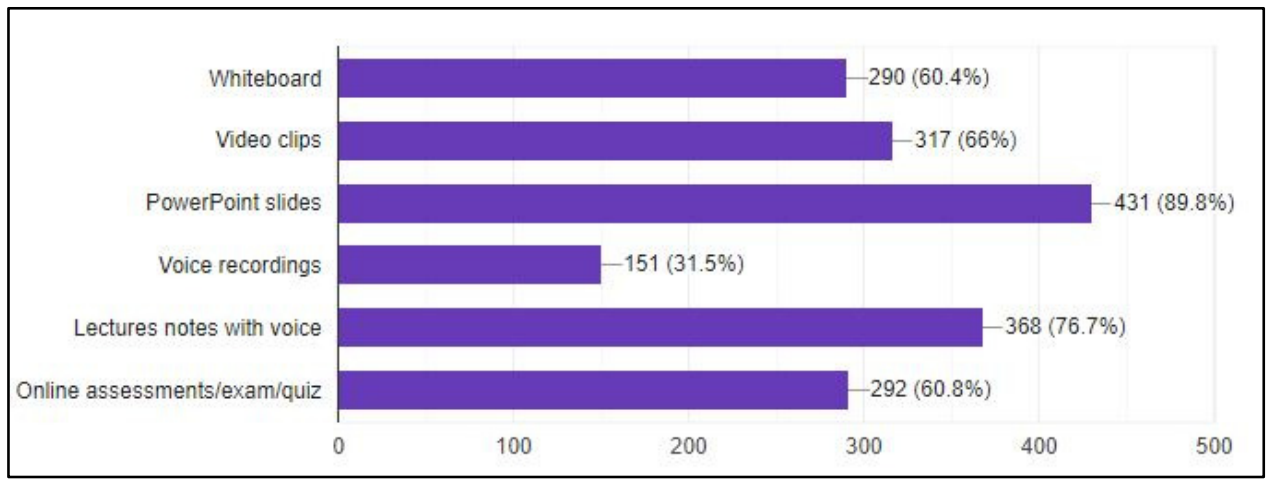

Figure 4: Types of teaching tools used for online teaching

Figure 4 illustrates the tools used for teaching activities by university teachers during the pandemic. The technology development showed that most of the teachers used PowerPoint Slides (89.8\%) to conduct their teaching activities. It is worthy of note that many teachers $(76.7 \%)$ provide lecture notes through voice only. Rather than teaching with the lecture materials, we noticed that many teachers shared video clips $(66 \%)$ related to their study area. However, several teachers used whiteboards $(60.4 \%)$ as part of their teaching technique. In addition, some teachers conducted lectures using only voice recordings (31.5\%). This pandemic situation required the teachers to conduct the quizzes and examinations, and do the student assessments through the online system. $60.8 \%$ of the students had to deal with the examinations, quizzes, and assessments through the online system.

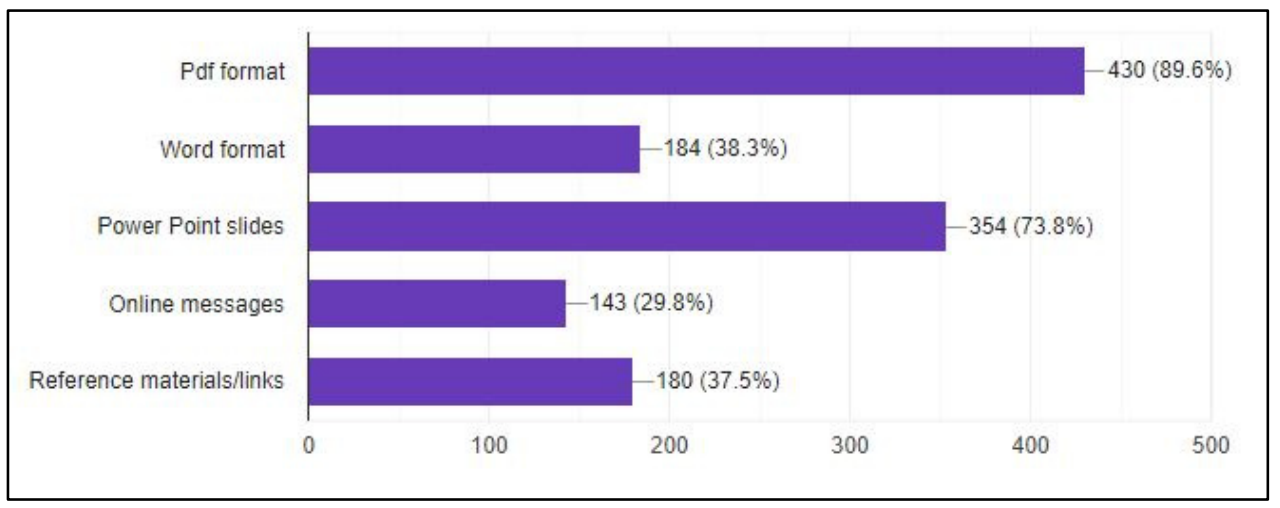

Figure 5: Types of Media used for Sharing Study Materials

As shown in Figure 5, the lecture materials are being sent online to facilitate the teaching and learning process. Most of the lecture materials have been sent in the PDF format (89.6\%) to date. PowerPoint slides $(73.8 \%)$ are also a routine way to deliver the lectures more efficiently. Other formats like MS Word (38.3\%), Reference materials/ links (37.5\%), and online messages (29.8\%) are also significant media for distributing lecture materials. 


\subsection{Challenges facing the online learning system}

Despite the pros and cons, this online learning system is indeed a boon for the students and teachers to keep them engaged in their learning and teaching activities in the present pandemic situation. Unfortunately, developing countries like Sri Lanka have been facing numerous obstacles in the way of the online learning system. Those obstacles can be classified under such categories as technical issues, economic issues, environmental issues, poor technological knowledge, and psychological hurdles.

These obstacles act as barriers to the teaching and learning process and present challenges in developing insight learning. We explain these obstacles with the help of Figure 6.

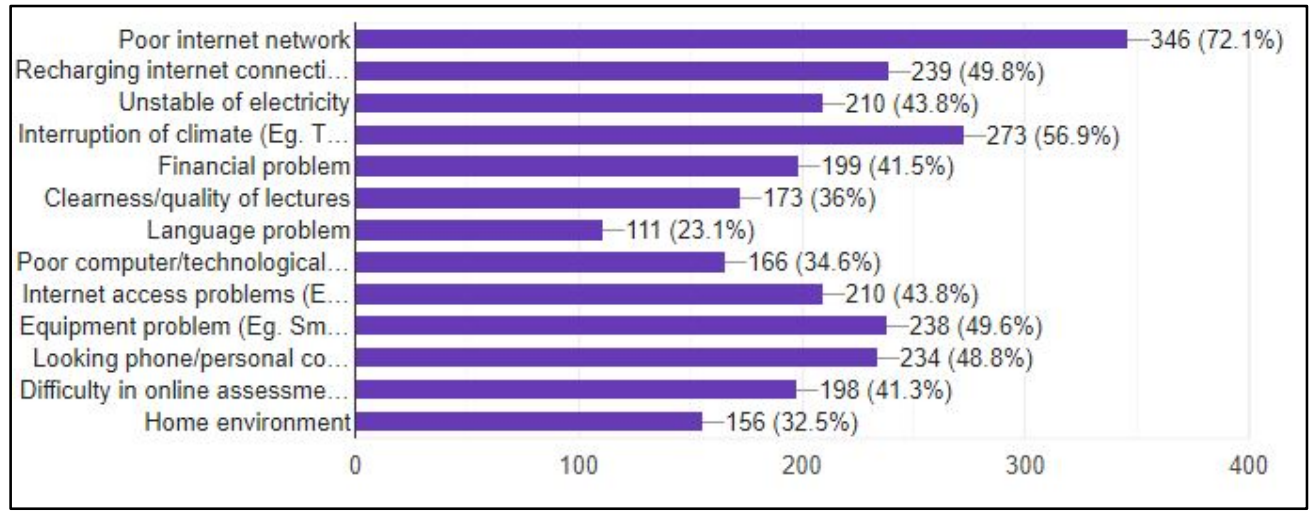

Figure 6: Problems encountered in online learning

Figure 6 clearly shows the types of problems that arise during online learning. The most vexing problem is usually poor Internet connectivity $(72.1 \%)$. Students also faced the problem of having to recharge their Internet connections frequently due to exhausting the data rapidly. Another major issue is unstable and unreliable electricity supply, which makes it impossible to recharge their phones and other devices (49.8\%). The unstable electricity can be a big hindrance to conducting lectures without interruption. Interruptions due to disturbances caused by bad weather $(56.9 \%)$ can prove to be another major issue in the way of online learning. Heavy rain, thunder, and lightning often interrupt the Internet connectivity or even cause damage to the electrical devices used for online learning.

According to the research, students are confronting many problems in pursuing their learning process online. Financial constraints $(41.5 \%)$, lack of clarity in lectures $(36 \%)$, language problem (23.1\%), poor technical skills (34.6\%), Internet access problem (43.8\%), equipment problem (49.6\%), stress/ boredom caused by looking at the computer/phone screen for a long time (48.8\%), difficulty in doing exams online (41.3\%), and unfavorable home environment for studying $(32.5 \%)$ have been identified as the most common problems after studying the collected data. These problems are interdependent on each other and so there is an interrelationship between them.

\subsection{Satisfaction and Confidence}

This research contains information gleaned from the data, about the students' level of satisfaction and confidence in online learning. Questions were asked about various learning and teaching processes in the questionnaire, and the respondents gave their opinions in terms of a graded scale ranging from very satisfied/highly confident to very dissatisfied/not at all confident. Overall results of 
the data interpretation show that $70.8 \%$ of students are satisfied while $74 \%$ of students have confidence in online learning. However, many students are dissatisfied and do not have much confidence in online learning. The figures are $27.1 \%$ and $24.1 \%$, respectively. Figure 7 depicts the students' satisfaction and confidence in online learning in the form of pie charts.
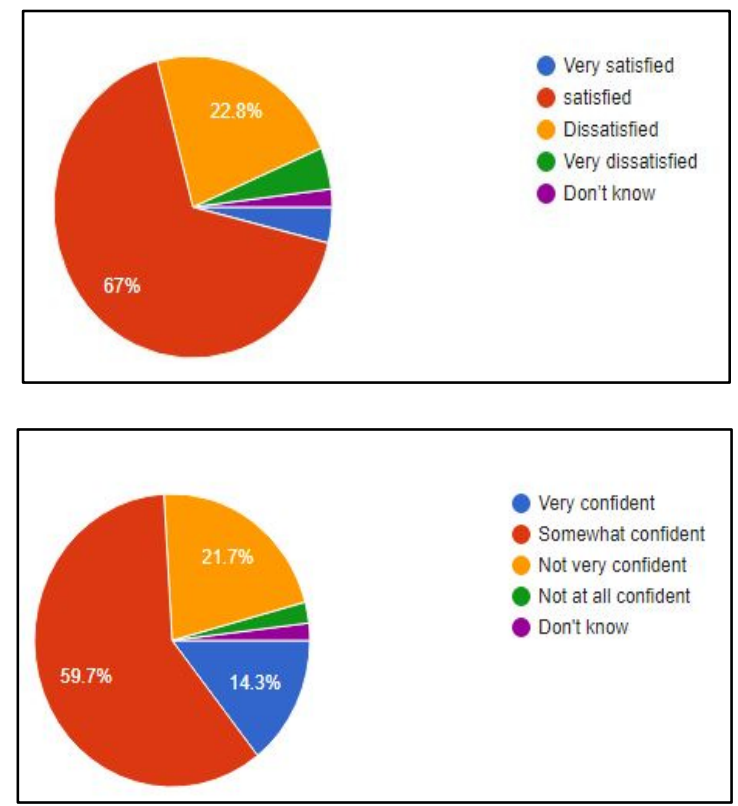

Figure 7: Students' satisfaction (a) and confidence (b) in online learning

As per the results of the data collection, it is clear that even though online learning provides an opportunity to continue the learning and teaching process, it does not facilitate the development of insight learning. Insight learning is mainly done by observation. This observation includes taking notice of the lectures, whiteboard, and/or computer/phone screen and perceiving the relationships and understanding the situation. The traditional classroom setup evolved according to the strategies and characteristics of the learning theories proposed by scholars and educationists.

Therefore, the traditional classroom environment provides many opportunities to understand what is taught and become familiar with the subject matter. However, the online classroom never provides this feeling because the classes are held in a different place and time and the teacher is physically absent. Out of the 484 respondents, $61.9 \%$ of students feel that the brick and mortar classroom is better than the online class. This corresponds to 298 students. Of these students, 214 strongly agree that the physical classroom provides more opportunities for focusing on the subject. Meanwhile, 199 students strongly agree, and 103 students partly agree, that a physical classroom is a better environment for learning.

Gestalt emphasizes that when an individual faces a problem, he thinks and looks over the whole situation and tries to find a solution. Thus, the structure of the physical classroom, the teacher's presence, the peer group interaction and interpretation, the immediacy of lectures and the subject matter, lay the way for the students to arrive at the solution through the development of insight. However, in the case of online learning, we can see that there are many obstacles in the way of attending virtual lectures. The obstacles are poor Internet networks, unstable electricity, and interruptions due to bad weather, that get in the way of the active learning process. So, if a student cannot attend the class and be an active learner, he will never understand the whole situation well 
enough to develop the necessary insight to find out the solution to the problem.

Interaction plays a significant role in developing insight. Interaction between an individual and his situation or environment, teacher and students, and the peer group learners, will inspire an individual to achieve insight learning successfully. In the case of online learning though, this interaction will be minimal and shallow. In a physical classroom there will be teachers, students, and peer groups working together in the learning process. When students are engaged in the remote learning process they are alone physically. So, active interaction will not be possible.

In the physical classroom, the teacher can make some adjustments to accommodate any special needs of the students. Even if the teacher has everything prepared for the lessons, he can still make a few changes to suit the classroom environment. Further, by making eye contact and taking note of the behavioral pattern of the students, he will be able to understand the students' state of mind and change his teaching pattern accordingly. But in the case of the online environment, the teacher would not even be aware if any changes should be made to the teaching process. There will also be minimal interaction between the students and teachers and little opportunity for clearing any doubts. Thus, this will not be student-centered learning, and there will be too much domination of teachers. Consequently, students will not have much freedom to develop insight.

Moreover, online learning can give rise to psychological issues among the students. Staring at the computer/ smartphone screen for long periods, financial constraints, unfavorable home environment, and problems in accessing technology were the 04 reasons most often cited as causing psychological stresses. According to the data, 48.6\%, 41.3\%, 32.4\%, and 34.7\% of students referred to these reasons, in that order. Hence, these obstacles stand in the way of students and prevent them from experiencing a truly effective learning experience. Therefore, the students are denied the opportunity to immerse themselves in the whole learning situation, and settle instead for a process that was never intended to develop insight.

\subsection{Suggestions for future online learning}

Based on the survey, $40.6 \%$ of students do not have a definite intention to choose online learning in the future, and that is the majority opinion. They selected 3 to give their opinion under the 1 to 5 scale system. Most of the students strongly agreed that online learning should be developed further, such as by providing further training in ICT to teachers and students, improving the curriculum, modifying the learning theories, developing tools for teaching, and expanding the network facilities. These suggestions show that online learning needs further improvement to become a more effective teaching/ learning process.

The foregoing observations suggest that online learning is not fulfilling its role as a satisfactory learning process for the students. Therefore, it is expected that further research on online learning may result in improvements that provide a better platform for students to learn effectively.

\section{Conclusion}

The Covid-19 pandemic has had different kinds of repercussions in different sectors across the world. Everyone has rushed out to find alternative ways of doing things in the face of the pandemic. In the case of the education sector, especially higher education, it is imperative to find a remedy to overcome the challenges faced by this vital sector during the pandemic period. To make the best use of technological developments to address the issues, the local institutions should discover how online learning is practiced in the developed countries, and how distance education is practiced online in some developing countries.

However, the sudden transition to online learning has presented many problems to the students and teachers. Although the higher educational institutions may claim they have made the required changes to their educational activities, there are more and more problems behind the scene. According to this study, we can state that applying the existing learning theories to online learning 
can create problems. Especially, the Gestalt learning theory needs more development before it can be applied to online learning successfully.

In future, the world will be far more dependent on technology. Even after the pandemic blows away, and the country reverts to its normal activities, the educational institutions should consider continuing with online learning, by including it in their teaching methodology. Teaching methods, approaches, strategies, and learning theories should be modified to accommodate the online learning system. Moreover, future pedagogical techniques should consider the combined use of physical and online education to familiarize the students and teachers with both systems.

\section{References}

Anderson, T. (2011). The theory and practice of online learning (2nd Edition). Edmonton, AB: AU Press.

Çeliköz, N., Erisen, Y., \& Sahin, M. (2019). Cognitive Learning Theories with Emphasis on Latent Learning, Gestalt and Information Processing Theories. Online Submission, 9(3), 18-33. Retrieved from https://files.eric.ed.gov/fulltext/ED598366.pdf.

Cvetkovic, D. (2016). Virtual Learning. ExLi4EvA.

Dhawan, S., (2020), 'Online Learning: A Panacea in the Time of COVID-19 Crisis'. Journal of Educational Technology Systems, 49(1), 5-22. DOI: doi.org/10.1177/0047239520934018.

Erandi, H., Mahasinghe, A.C., Perera, S., Jayasinghe, S. (2020). Effectiveness of the Strategies Implemented in Sri Lanka for Controlling the COVID-19 Outbreak. medRxiv 2020.04.27.20082479. https://doi.org/10.1101/2020.04.27.20082479

Hayashi, R., Garcia, M., Maddawin, A., \& Hewagamage, K.P. (2020). Online learning in Sri Lanka's higher education institutions during the COVID-19 pandemic. ADB Briefs, DOI: dx.doi.org/10.22617/BRF20026o-2

Hu, H., \& Driscoll, M.P., (2013). Self-Regulation in e-Learning Environments: A Remedy for Community College? Journal of Educational Technology \& Society, 16(4), 171-184. Retrieved from https://www.jstor.org/stable/jeductechsoci.16.4.171.

Kamari, K.W.S.N., \& Jayasinghe, G.J.M.S.R. (2021). Undergraduate Students' Readiness for Blended Learning During COVID-19 Pandemic in Sri Lanka. DOI: http://dx.doi.org/10.2139/ssrn.3831219.

Koffka, K. (1936). Principles of Gestalt Psychology. USA: Harcourt, Brace and Company.

Koffka, K. (1936). Principles of Gestalt Psychology. USA: Harcourt, Brace and Company.

Köhler, W. (1925). The mentality of Apes. New York, NY: Harcourt, Brace \& Company Inc.Google Scholar.

Manoharan, E. (2009). Educational Psychology (Vol. I). Sri Lanka - Akkaraipattu: New Selection Offset Printers.

Ovens, M. (2017). Do Learning Theories Matter In Classroom Teaching?: The role of learning theories in the teaching of a service course in undergraduate statistics. Retrieved from https://www.yourstatsguru.com/epar/ourpublications/ovens2o17/.

Picciano, A. G. (2017). Theories and frameworks for online education: Seeking an integrated model. Online Learning, 21(3), 166-190. DOI: 10.24059/olj.v21i3.1225.

Rameez, A., Fowsar, M.A.M., \& Lumna, N. (2020). Impact of Covid-19 on Higher Education Sectors in Sri Lanka: A study based on South Eastern University of Sri Lanka. Journal of Educational and Social Research, 10(6): 341 . https://doi.org/10.36941/jesr-2020-0132

Roddy, C., Amiet D.L., Chung, J., Holt, C., Shaw, L., McKenzie, S., Garivaldis, F., Lodge, J.M., \& Mundy, M.E. (2017). Applying Best Practice Online Learning, Teaching, and Support to Intensive Online Environments: An Integrative Review. DOI: 10.3389/feduc.2017.00059

Rupasinghe, R.A.H.M., \& Haththotuwa, P.M.P.S. (2021). Adapting to online learning in higher education system during the Covid-19 pandemic: A case study of universities in Sri Lanka. Sri Lanka Journal of Social Sciences and Humanities, 1(2), 147-16o. Retrieved from https://www.sab.ac.lk/sljssh/articles/issue-1-2/sljssh-1(2)-14.pdf.

Simonson, M., \& Schlosser, A. (2006). Distance education: Definition and Glossary of terms, ( ${ }^{\text {rd }}$ ed.). Greenwich: Information Age Publishing. Retrieved from https://www.researchgate.net/publication/40822235_DIST ANCE_EDUCATION_Definition_and_Glossary_of_Terms_3RD_EDITION.

Temdee, P. (2020). Smart Learning Environment: Paradigm Shift for Online Learning, Multi Agent Systems Strategies and Applications. Ricardo López - Ruiz, IntechOpen, DOI: 10.5772/intechopen.85787.

Weerathunga, P.R., Samarathunga, W.H.M.S., Rathnayake, H.N., Agampodi, S.B., Nurunnabi, M., \& Madhunimasha, M.M.S.C. (2021). The COVID-19 Pandemic and the Acceptance of E-Learning among University Students: The Role of Precipitating Events. DOI: doi.org/ 10.339o/educsci11080436.

Weiss, J., Nolan, J., Hunsinger, J., \& Trifonas, P. (2006). The International Handbook of Virtual Learning Environments (Vol. I). Netherland: Springer. 